\title{
CULTURALLY RESPONSIVE TEACHING OF IMMIGRANTS IN ADULT EDUCATION: A CASE STUDY IN SWEDEN
}

\author{
Andreas Ahrens' ${ }^{1}$ Jelena Zascerinska ${ }^{2}$, Julija Melnikova ${ }^{3}$, \\ Virginija Jurgaityte ${ }^{4}$, Ludmila Aleksejeva ${ }^{5}$, Olga Gukovica ${ }^{6}$ \\ ${ }^{1}$ Dr.-Ing. habil., professor, Hochschule Wismar, Wismar, Germany, \\ e-mail: andreas.ahrens@hs-wismar.de \\ 2 Dr. Paed., leading researcher, Centre for Education and Innovation Research, Riga, \\ Latvia, e-mail: iizi.info@inbox.lv \\ ${ }^{3}$ Dr., lecturer, Klaipeda University, Klaipeda, Lithuania, \\ e-mail: julijamelnikova@yahoo.com \\ ${ }^{4}$ MA., lecturer, Klaipeda University, Klaipeda, Lithuania, e-mail: svenska.ku@gmail.com \\ ${ }^{5}$ MA, lesearcher, Centre for Education and Innovation Research, Riga, Latvia, \\ e-mail: asava@inbox.lv \\ ${ }^{6} \mathrm{BA}$, scientific assistant, Centre for Education and Innovation Research, Riga, Latvia, \\ e-mail: ceir2012@gmail.com
}

Received: 26 June 2020 / Revised: 14 July 2020 / Accepted: 22 July 2020 /

Published: 30 November 2020

\begin{abstract}
Adult education has been criticized for its lack of focus on sociocultural aspects of individual learners, largely ignoring the importance of cultural identity to the learning process. The paper's aim is to investigate culturally responsive teaching of immigrants in adult education, theoretically and empirically underpinning the implementation of a case study for the elaboration of implications on culturally responsive teaching of immigrants in adult education. Research methods include theoretical and empirical methods. Theoretical methods imply analysis of theoretical sources and theoretical modelling. The empirical study was based on a case study. The sample was composed of 20 adult learners and three teachers of Swedish in May 2019 and February 2020. The case study was implemented at Folkuniversitetet, Kristianstad, Sweden. The theoretical findings allow defining religion and human comfort conditions such as thermal comfort as the dimensions of cultural norms and values to be addressed by culturally responsive teaching of immigrants. The findings of the empirical study allow drawing the conclusion on the necessity of a personalised approach to an adult learner in culturally responsive teaching of immigrants. The novelty of the present work is revealed in the implications on culturally responsive teaching of immigrants. Further research is proposed.
\end{abstract}

Keywords: adult education, culturally responsive teaching, immigrants, case study, interpretive approach.

JEL code: I24, I25.

\section{Introduction}

Human migration will be only increasing in the coming years due to a number of factors. One of such factors is climate change (Pinto-Dobernig, 2008, p. 9). Millions of people will be displaced by shoreline erosion, coastal flooding and agricultural disruption (Pinto-Dobernig, 2008). On the other hand, some European countries (including Baltic Sea countries such as 
Estonia, Germany, Latvia and Lithuania and other) face unbalance in their labour markets due to demographic decline and skills shortages (Melnikova, Zaščerinska, 2018). For a successful integration of immigrants into the socioeconomic situation of a host country, social and integration services have to take the immediate response and to provide sufficient support to integrate newcomers into the host society and get them on a path to economic self-sufficiency (Melnikova, Zaščerinska, 2018). Since the power of adult learning was discovered (Zaščerinska, Aḷeksejeva, Aḷeksejeva, Andreeva, Glonina, Zaščerinskis, 2015), the demand for adult learning, including for immigrants, is permanently increasing (Melnikova, Ahrens, Zaščerinska, 2019). In adult education, the importance of the individual in the learning process is permanently highlighted, however adult education has been criticized for its lack of focus on sociocultural aspects of individual learners, largely ignoring the importance of cultural identity to the learning process (Melnikova, Kuprienè, Jurgaitytė, Zascerinska, Blažulionienė, 2020).

The scientific problem reflected in the paper is formulated as the research question: How to organise culturally responsive teaching of immigrants in adult education? The aim of the present paper is to investigate culturally responsive teaching of immigrants in adult education, theoretically and empirically underpinning the implementation of a case study for the elaboration of implications on culturally responsive teaching of immigrants in adult education. The tasks of the research are:

- To define culturally responsive teaching of immigrants in adult education.

- To carry out a case study.

- To elaborate implications on culturally responsive teaching of immigrants in adult education.

- To draw conclusions.

The novelty of the present work is revealed in the formulated implications on culturally responsive teaching of immigrants in adult education.

Research methods applied include the use of theoretical as well as empirical methods. Theoretical methods imply analysis of theoretical sources and theoretical modelling (Ahrens, Zascerinska, Melnikova, 2019). The empirical study was based on a case study. The exploratory type of the case study research has been applied (Zainal, 2007), as case studies have an important function in generating new research questions, hypotheses and building theory (Kohlbacher, 2005). Exploratory case studies set to explore any phenomenon in the data which serve as a point of interest to the researcher (Zainal, 2007). The present case study belongs to the qualitative methodology. The qualitative methodology implies the use of the interpretive approach to case studies. The interpretive approach/paradigm 
is featured by the researcher's interest in a phenomenon. The interpretive paradigm is aimed at analysing the social construction of the meaningful reality. Meanings emerge from the interpretation. The researcher is the interpreter (Ahrens, Purvinis, Zascerinska, Miceviciene, Tautkus, 2018). The interpretive paradigm is underpinned by naturalistic methods such as observation and interpretation, thus to observe is to collect information about events, while to interpret is to make a meaning of that information by drawing inferences or by judging the match between the information and some abstract pattern (Aikenhead, 1997). Interviewing as a method of data collection within the interpretive paradigm allows ensuring a cultural dialogue between the researcher(s) and participant(s) of the case study for joint discovery of a shared meaning of the investigated phenomenon in the common environment. The methodology of the exploratory type of the case study research is divided into logical and sequential phases. The methodology of the present research proceeds from exploration in Phase 1 through analysis in Phase 2 to implication development in Phase 3.

Observation was employed as a basis of data collection. Observation is a highly effective method of qualitative data obtaining (Zaščerinska, 2013). Observation makes use of a number of techniques, namely, document analysis, respondent interviewing and students' self-analysis (McCall, \& Simmons, 1969, p. 1). Moreover, observation contributes to a more adequate picture that emerges of the research setting as a social system described from a number of participants' perspectives (Geertz, 1973; Burgess, 1984), namely culturally responsive teaching of adult learners with the migrant background. Furthermore, Hargreaves (Hargreaves, 1967, 193) described advantages of participant observation as a research method for those carrying out studies in institutions in which they work: the method of participant observation leads the investigator to accept a role within the social situation $\mathrm{s} /$ he studies $-\mathrm{s} /$ he participates as a member of the group while observing it. In theory, this direct participation in the group life permits an easy entrance into the social situation by reducing the resistance of the group members; decreases the extent to which the investigator disturbs the 'natural' situation, and permits the investigator to experience and observe the group's norms, values, conflicts and pressures, which (over a long period) cannot be hidden from someone playing an in-group role (Hargreaves, 1967).

A non-structured or, in other words, unstructured interview was implemented to search for the main categories of the research field (Kroplijs, Rascevka, 2004). A non-structured interview is conventionally built on a certain topic to be disclosed during the meeting. However, a non-structured interview does not imply any specific set of predetermined questions. A non- 
structured interview is organised in a non-formal manner and tends to be open-ended.

The data were studied via a content analysis. The content analysis included a structuring content analysis and a summarizing content analysis (Mayring, 2000). Structuring content analysis assists in categorising the data in accordance to the previously determined criteria (Budde, 2005). In turn, summarizing content analysis seeks to reduce the material in such a way that the essential contents are preserved, but a manageable short text is produced (Mayring, 2004).

Only a few respondents as a case for the study participated in the empirical study, as a qualitative research design has been employed (Kohlbacher, 2005). The qualitatively oriented empirical study allows the construction of only few cases (Mayring, 2004). Moreover, the cases themselves are not of interest, only the conclusions and transfers we can draw from these respondents (Flyvbjerg, 2006). Selecting the cases for the case study comprises use of information-oriented sampling, as opposed to random sampling (Flyvbjerg, 2006). This is because an average case is often not the richest in information. In addition, it is often more important to clarify the deeper causes behind a given problem and its consequences than to describe the symptoms of the problem and how frequently they occur (Flyvbjerg, 2006). Random samples emphasizing representativeness will seldom be able to produce this kind of insight; it is more appropriate to select some few cases chosen for their validity (Flyvbjerg, 2006).

The present sample was composed of nine adult learners and two teachers of Swedish in May 2019 and 11 adult learners and one teacher of Swedish in February 2020. Adult learners and one teacher of Swedish were with the migrant background, two other teachers of Swedish were of the Swedish origin. The case study was organised at Folkuniversitetet, Kristianstad, Sweden. Folkuniversitetet, Kristianstad, Sweden, was chosen for the implementation of the case study as Folkuniversitetet in Kristianstad obtained rich experience in teaching immigrants during many years. In order to save the information of the present research confidential, the respondents' names and surnames are not revealed.

The enabling research question (hypothesis) is formulated as following: What is culturally responsive teaching of immigrants?

\section{Research results and discussion}

Culturally responsive education is the overall concept that includes culturally responsive teaching. Culturally responsive education is an approach to address the needs of today's diverse classroom (Melnikova, Kuprienè, Jurgaitytė, Zascerinska, Blažulionienè, 2020). Table 1 (Gruenwald, 
Ahrens, Zaščerinska, Melnikova, Andreeva, 2018) demonstrates the dimensions of cultural norms and values in a classroom.

Culturally responsive teaching is an approach to address diversity (Melnikova, Kuprienè, Jurgaitytė, Zascerinska, Blažulionienè, 2020) in adult education. In contrast to traditional pedagogies, the culturally responsive framework places learners' cultures at the core of the learning process and utilizes the "cultural knowledge, prior experiences, frames of reference, and performance styles of ethnically diverse students" (Gay, 2000).

Table 1. Cultural norms and values in a classroom (Gruenwald, Ahrens, Zaščerinska, Melnikova, Andreeva, 2018)

\begin{tabular}{|c|c|c|}
\hline $\begin{array}{c}\text { Dimensions of } \\
\text { cultural norms } \\
\text { and values }\end{array}$ & $\begin{array}{c}\text { International students' cultural } \\
\text { norms and values }\end{array}$ & $\begin{array}{c}\text { Host country's educators' } \\
\text { cultural norms and values }\end{array}$ \\
\hline Person's name & Surname and first name & First name and surname \\
\hline Time & Stretchable time & Punctuality \\
\hline People address & "Sir" or "Ma'am,","Mr." "Ms." "Mrs." & Person's title and surname \\
\hline Politeness & Smile and nod of the head & "Please" and "Thank you" \\
\hline
\end{tabular}

Culturally responsive education can be identified by the following common characteristics:

- It acknowledges the legitimacy of the cultural heritages of various ethnic groups, both as legacies that affect students' dispositions, attitudes, and approaches to learning and as worthy content to be taught in the formal curriculum.

- It builds meaningfulness between home and school experience as well as between academic abstractions and lived sociocultural realities.

- It uses a wide variety of instructional strategies that are connected to different learning styles.

- It teaches students to know and praise their own and each other's cultural heritages.

- It incorporates multicultural information, resources, and materials in all the subjects (Gay, 2000).

A model of culturally responsive education was designed. The framework entails the following four elements (Wlodkowski, Ginsberg, 1995): establishing inclusion, developing attitude, enhancing meaning, and engendering competence. The functions of each element are described as follows (Melnikova, Kuprienè, Jurgaitytė, Zascerinska, Blažulionienė, 2020):

- Teaching practices that create an environment of respect and connectedness and that use cooperation and equitable treatment of all learners reflect the element of establishing inclusion. 
- The element of developing attitude includes norms and practices that help students develop a positive attitude toward the learning process by building on the students' personal experiences and knowledge and by allowing the learners to make choices throughout the learning process.

- The third element, enhancing meaning, includes norms and practices that encourage students to engage in deep reflection and critical inquiry, such as roleplays and simulations.

- The final element, engendering competence, is practices that show the learner evidence of his or her learning and proficiency and the use of assessments that are contextualized in the learners' experiences.

This four-element model serves as the theoretical foundation for culturally responsive teaching practices applicable to the adult education (Melnikova, Kuprienė, Jurgaitytė, Zascerinska, Blažulionienė, 2020).

Recommendations for all the participants of culturally responsive teaching were proposed (Melnikova, Kuprienè, Jurgaitytè, Zascerinska, Blažulionienè, 2020): to pay attention to your own prejudices and biases, to listen to others, to ask questions rather than make assumptions, and to cultivate knowledge about other cultures.

Culturally responsive educators, who are the key organisers of culturally responsive teaching of immigrants, are proficient at discerning subtle and overt differences and developing culturally-sensitive and appropriate learning environments (Guy, 1999). In adult education, teachers and educators are supposed to develop social interactions, maintain fluid student-teacher relationships, demonstrate connectedness with all the students, develop a community of learners, encourage students to learn collaboratively and be responsible for another (Melnikova, Kuprienè, Jurgaitytė, Zascerinska, Blažulionienė, 2020). This culturally responsive education or, in other words, equity pedagogy (Banks, 2006), encompasses a variety of approaches such as culturally relevant, culturally sensitive, culturally congruent, and culturally contextualized pedagogies (Gay, 2000). For adult educators, such recommendations were proposed (Melnikova, Kuprienè, Jurgaitytė, Zascerinska, Blažulionienè, 2020):

- Integrate multicultural knowledge into the curricula to lessen the cultural divide.

- Acknowledge cultural differences among immigrant groups.

- Foster inclusive learning communities through use of learning partners or teams.

- De-emphasize assimilation in curricula and teaching practices.

- Consider work socialization of immigrant groups.

A training session of Swedish as a foreign language was observed in May 2019. The topic of the training was devoted to the preparation of a CV and a 
covering letter, as the adult learners aim at getting a job or starting a company in the host country. Local companies in a host country employ immigrant for establishing business connections between the immigrants' host country as well as the immigrants' origin country (Ahrens, Zaščerinska, 2020). Employment of immigrants who communicate in a language of the country local companies do business with is beneficial for all the stakeholders, namely the host country' companies, partners of the host country' companies, and the employed immigrant (Ahrens, Zaščerinska, 2020) in terms of improvement of opportunities in the economic, social and civic life of their new country (Pieroni, d'Agostino, Lanari, 2019). The training was implemented by two teachers of Swedish of the Swedish origin in the Swedish language only. One of the teachers was a male teacher, the other - female. Another training of Swedish as a foreign language was studied in February 2020. The topic of the training was preparation for the examination in Swedish for immigrants (SFI). The training detailed the structure of the examination organisation (listening, reading, speaking and writing). The teacher was a female with the immigrant background. The teacher's migrant background differed from the adult learners' migrant background. The observation revealed that this teacher of Swedish was more expressive in comparison to two teachers of Swedish of the Swedish origin. She used gestures for demonstrating the point she was explaining to the adult learners. For example, she was pretending that she was writing while speaking about the writing part of the examination. Also, the teacher drew simple symbols such as time, schedule, maps, plans, etc. on the blackboard for clarifying the examination procedural details.

In both observed classes, the adult learners originally came from Syria, Poland, Croatia, etc. The students belonged to different age groups: 20-30 years old as well as 35-50. The students were in coats and jackets despite the temperature in the classroom was adequate. Some of the students were late for the training.

In the interview, two teachers of Swedish of the Swedish origin highlighted the importance of learning Swedish for the future employment and careers of immigrants in the host country. The teacher of Swedish with the migrant background emphasized during the interview that there were no discussions about religion, war and the current situation in the countries adult learners arrived from in a class. This teacher experienced a couple of situations where a migrant husband attended the same training his wife was involved in. This wife brought her books as well as her husband's books to the class. Such a situation was not discussed with anyone. But after some time, the wife rejected to take care of the books of her husband. The teacher also pointed out that if a class is missed by an adult learner, it can be 
discussed with the adult learner who did not attend the class only individually.

The findings of the empirical study carried out demonstrate that contemporary adult education experiences cultural diversity. In a host country, not only adult learners but also teachers might have a migrant background. The structuring content analysis allows extending the dimensions of cultural norms and values, namely the person's name, time, people's address, politeness (Gruenwald, Ahrens, Zaščerinska, Melnikova, Andreeva, 2018) by religion and human comfort conditions such as thermal comfort. The summarising content analysis highlights that the culturally responsive teaching of immigrants requires a personalised approach to an adult learner.

\section{Conclusions and suggestions}

The theoretical findings of the present research allow defining religion and human comfort conditions such as thermal comfort as the dimensions of cultural norms and values to be addressed by culturally responsive teaching of immigrants. The findings of the empirical study allow drawing the conclusion on the necessity of a personalised approach to an adult learner in culturally responsive teaching of immigrants. The empirical study assisted in the finding that not only adult learners' but also teachers' migrant backgrounds make adult education classes diverse.

Implications for culturally responsive teaching of immigrants in adult education include the implementation of a personalised approach to an adult learner in culturally responsive teaching of immigrants in adult education. The personalised approach implies considering the dimensions of cultural norms and values, such as the person's name, time, people's address, politeness (Gruenwald, Ahrens, Zaščerinska, Melnikova, Andreeva, 2018), religion and human comfort conditions such as thermal comfort.

The present research has limitations. The inter-connections between culturally responsive teaching of immigrants and dimensions of cultural norms and values have been set. Another limitation is the empirical study conducted by involving the respondents of one institution only.

The further research will focus on the involvement of respondents from other institutions into the empirical study. A comparative study of different countries could be interesting for the research community as well. 


\section{Acknowledgement}

The present work has been carried out within the Nordplus Adult project 2019 entitled "Development of digital entrepreneurship: addressing the needs of immigrants and asylum seekers".

\section{References}

1. Ahrens, A., Purvinis, O., Zaščerinska, J., Miceviciene, D., Tautkus, A. (2018). Burstiness Management for Smart, Sustainable and Inclusive Growth: Emerging Research and Opportunities. IGI Global. DOI: 10.4018/978-1-5225-5442-4

2. Ahrens, A., Zaščerinska, J. (2020). Immigrants' Use of Language for Professional Purposes in a Host Country: Implications for Adult Education. SOCIETY. INTEGRATION. EDUCATION Proceedings of the International Scientific Conference, V, 335-345. http://dx.doi.org/10.17770/sie2020vol5.4860.

3. Ahrens, A., Zaščerinska, J., Melnikova, J. (2019). Method for the Construction of Students' Scientific Identity within English for Academic Purposes: The Case of International Students of Master Programme "Information and Electrical Engineering" at Hochschule Wismar. SOCIETY. INTEGRATION. EDUCATION. Proceedings of the International Scientific Conference, I, 43-53. DOI: http://dx.doi.org/10.17770/sie2019vol1.3731

4. Aikenhead, G. S. (1997). A framework for reflecting on assessment and evaluation Globalization of Science Education: International Conference on Science Education. Seoul, Korea the Korean Education Development Institute.

5. Banks, J. (2006). Cultural Diversity and Education. Pearson.

6. Budde, R. (2005). Mexican and Central American L.A. Garment Workers: Globalized Industries and their economic constraints. LIT Verlag Münster.

7. Burgess, R. G. (1984). In the Field. An introduction to field research. London: George Allen \& Unwin.

8. Flyvbjerg, B. (2006). Five Misunderstandings About Case-Study Research. Qualitative Inquiry,12(2), 219-245.

9. Gay, G. (2000). Culturally Responsive Teaching: Theory, Research, and Practice. New York: Teachers College Press.

10. Geertz, C. (1973). The Interpretation of Cultures. London: Hutchinson.

11. Gruenwald, N., Ahrens. A., Zaščerinska, J., Melnikova, J., Andreeva, N. (2018). SocioCultural Adaptation of International Students of Master Programme "Information and Electrical Engineering" at Hochschule Wismar. Proceedings of the 5th International Scientific Conference on "Modern Economics". 14-16 May 2018, Vigo, Spain, 33-39.

12. Guy, T. (1999). Culture as context for adult education: The need for culturally relevant adult education. In T. C. Guy (Ed.), Providing Culturally Relevant Adult Education 5-18, New Directions for Adult \& Continuing Education, No. 82. JosseyBass, U.S.A.

13. Hargreaves, D. H. (1967). Social Relations in a secondary school. London: Routledge and Kegan Paul.

14. Kohlbacher, F. (2005). The Use of Qualitative Content Analysis in Case Study Research. Forum: Qualitative Social Research, 7(1), Art. 21, 
15. Kroplijs, A., Rascevska, M. (2004). Kvalitatīvās pētniecības metodes sociālajās zinātnēs [Qualitative research methods in social sciences]. Rīga: RaKa. .

16. Mayring, P. (2000). Qualitative Content Analysis. Forum: Qualitative Social Research, 1(2), Art. 20, Retrieved from http://nbn-resolving.de/urn:nbn:de:0114fqs0002204.

17. Mayring, P. (2004). Qualitative Content Analysis. In: U. Flick, E. Von Kardoff and I. Steinke (Eds). A Companion to Qualitative Research, 266-269. SAGE, UK, Glasgow.

18. McCall, G. J. and Simmons, J. L. (eds.) (1969). Issues in Participant Observation, Reading, Mass. Addison Wesley.

19. Melnikova J., Zaščerinska J. (2018). Fostering the integration of immigrants and asylum seekers into labour market in Baltic countries: opportunities of digital entrepreneurship. International relations and international law journal, 4(84), 9096.

20. Melnikova, J., Ahrens, A., Zaščerinska, J. (2019). National Insights from Lithuania, Latvia and Poland for EU Adult Education Policy Development. SOCIETY. INTEGRATION. EDUCATION. Proceedings of the International Scientific Conference. V. 233-243. DOI: http://dx.doi.org/10.17770/sie2019vol5.3986.

21. Melnikova, J., Kuprienè, L., Jurgaitytė, V., Zascerinska, J., Blažulionienè, S. (2020). Culturally Responsive Education of Migrants in Klaipeda Region The 16th international conference „Social Innovations for Sustainable Regional Development”: Klaipėda, Lithuania, April 29, 2020.

22. Pieroni, L., d'Agostino, G., Lanari, D. (2019). The effects of language skills on immigrant employment and wages in Italy. MPRA Paper No. 91725, posted 29 Jan 2019 16:22 UTC.

23. Pinto-Dobernig, Ilse. (2008). Migration and Climate Change, Nr.31. International Organization for Migration. ISSN 1607-338X.

24. Wlodkowski, R., Ginsberg, M. (1995). A Framework for Culturally Responsive Teaching. Educational leadership: journal of the Department of Supervision and Curriculum Development, N.E.A · January 1995

25. Zainal, Z. (2007). Case study as a research method. Jurnal Kemanusiaan bil.9, Jun 2007.

26. Zaščerinska, J. (2013). Development of Students' Communicative Competence within English for Academic Purposes Studies. Berlin: Verlag Mensch \& Buch.

27. Zaščerinska, J., Aḷeksejeva, A., Aḷeksejeva, L., Andreeva, N., Gloṇina, O., Zaščerinskis, M. (2015). E-Learning in Non-Formal Adult Education in Latvia: Context Analysis. Verlag: Mensch \& Buch. 